\title{
DINÁMICAS ESTATALES EN LA GLOBALIZACIÓN: EL ROL DE LOS ESTADOS SUBNACIONALES FRENTE A LA LLEGADA DE CALL CENTERS EN ARGENTINA ${ }^{1}$
}

\author{
Eric Moench \\ Estudiante de la Maestría en Ciencias Sociales del Trabajo \\ Universidad de Buenos Aires, Bs. As. (Argentina) \\ Correo electrónico: moench.eric@gmail.com
}

Recibido: 25 de mayo de 2011. Aceptado: 10 de junio de 2011

\section{RESUMEN}

El proceso de globalización económica de las dos últimas décadas ha transformado el mapa productivo, social y político mundial. Uno de sus mayores impactos sobre América Latina se observa en las transformaciones operadas en la estructura y funciones de los estados nacionales y subnacionales. En Argentina luego de la devaluación se acelera la llegada de inversiones extranjeras directas que obtienen ventajas impositivas y subsidios estatales de magnitud. La significativa expansión de la actividad de los call centers (CCs) transnacionales que se localizan masiva y vertiginosamente en las principales ciudades argentinas en los últimos años dan cuenta de estos fenómenos y permiten abordar las transformaciones de las instancias estatales, en tanto visibilizan este rol regulador de las actividades económicas en los territorios.

El presente trabajo indaga en el rol y accionar de los estados subnacionales desde una perspectiva sociológica: se sistematizan y describen las leyes-decretos-convenios orientados a captar empresas de CCs y se analizan los debates parlamentarios que enmarcan y otorgan sentido a tales concesiones. Esta mirada permitirá visibilizar mecanismos de cooperación y/o conflicto mediante los cuales actores locales y extranjeros modelan la inserción de lo global en lo local. Finalmente, nos permite reflexionar acerca de las (a)simetrías de poder entre los actores estatales y los agentes económicos transnacionalizados, en el marco de espacios locales en tiempos de globalización.

Palabras clave: Transformaciones estatales, Roles y acciones de estados subnacionales, Globalización económica, Call centers

\begin{abstract}
The process of economic globalization in the last two decades has transformed the production, social and political world map. One of the largest impacts on Latin America is seen in the transformations in the structure and functions of national and subnational states. In Argentina after the devaluation the arrival of foreign direct investment is

1 Se agradecen los comentarios y sugerencias de Marta Panaia, de valioso aporte para que el autor elabore el presente artículo.
\end{abstract}


accelerated that get tax breaks and state subsidies of magnitude. The significant expansion of the transnational call centers (CCs) activity and rapidly mass located in major Argentine cities in recent years account for these phenomena and let address these transformations of the state agencies, because it makes visible the regulation role of economic activities in the territories.

This paper focuses on the role and actions of the provinces states from a sociological perspective, we systematize and describe the laws, decrees and agreements designed to attract CCs companies and analyzes parliamentary debates that frame and give meaning to such concessions. This view will visualize mechanisms of cooperation and / or conflict through which local and foreign actors shape the global integration into the local. Finally, we can think about (a)symmetry of power between state actors and economic transnationalized agents, in the context of local spaces in globalization times.

Key words: Change state, Roles and actions of subnational states, Economic globalization, Call centres

\section{INTRODUCCIÓN}

El proceso de globalización económica de las dos últimas décadas ha transformado el mapa productivo, social y político mundial. Uno de sus mayores impactos sobre América Latina se observa en las transformaciones operadas en la estructura y funciones de los estados nacionales y subnacionales ${ }^{2}$.

Las habituales jerarquías escalares de los actores estatales (desde lo nacional a lo local) se disuelven para dar paso a nuevas formas de funcionamiento. Desde esta perspectiva podemos observar cómo se han desplazado funciones reguladoras de las actividades económicas desde los estados nacionales hacia los estados subnacionales y, entre los roles que estos últimos desempeñan, se destaca el de atraer inversiones extranjeras. Dichas inversiones llegan de forma acelerada en el sector de servicios a las empresas: una importante porción se orientan a desarrollar actividades de baja jerarquización, en donde la competitividad se obtiene vía la baja del costo laboral y vía ventajas impositivas y subsidios estatales hacia las empresas.

La significativa expansión de la actividad de los call centers (CCs) transnacionales que se localizan masiva y vertiginosamente en las principales ciudades argentinas luego de la devaluación dan cuenta de estos fenómenos y permiten abordar estas transformaciones de las instancias estatales, en tanto visibilizan este rol regulador de las actividades económicas en los territorios.

Estas transformaciones y la reformulación del accionar estatal opera sobre estructuras y funciones históricamente constituidas y sedimentadas: no podemos comprenderlas acabadamente si no entendemos la historia de su propio accionar previo. En este sentido, observamos que luego de los años '90 las acciones de las instancias estatales subnacionales han tenido mayor impacto social y económico sobre el territorio local.

2 Bajo la denominación de estados subnacionales agrupamos aquí a las instancias estatales provinciales y municipales. 
Por su parte, los agentes económicos involucrados en la actividad de CCs recurren a la intervención estatal para lograr o mantener cuestiones fiscales de privilegio y para subsidiar sus costos laborales y edilicios, en vistas de la maximización de su rentabilidad.

En este contexto, este artículo indaga en el rol y accionar de los estados subnacionales desde una perspectiva sociológica: se sistematizan y describen las leyes-decretosconvenios orientados a captar empresas de CCs y se analizan los debates parlamentarios que enmarcan y otorgan sentido a tales concesiones. Esta mirada permitirá visibilizar mecanismos de cooperación y/o conflicto mediante los cuales actores locales y extranjeros posibilitan y modelan la inserción de lo global en lo local.

Asimismo intentaremos reflexionar acerca de las (a)simetrías de poder entre los actores estatales y los agentes económicos transnacionalizados a partir de la descripción de la instalación de CCs y la regulación estatal que acompaña su llegada en la provincia de Córdoba.

\section{EL ESTADO COMO ACTOR REGULADOR DE LA ECONOMÍA: CONTEXTO HISTÓRICO, DEBATES TEÓRICOS Y REFORMULACIÓN DE FUNCIONES}

\section{Las transformaciones del estado nacional en el contexto global}

Si bien la mayor parte de la actividad económica sigue teniendo carácter nacional o local, el núcleo básico, el que marca los ritmos y orientaciones de inversión e influye sobre los mercados, es global.

En este contexto económico-productivo, muchos autores han tomado nota de que se han producido reformulaciones en la estructura y funcionamiento de los actores estatales. Sin embargo, se plantean disidencias en torno al rol que les ha tocado cumplir. Algunos autores señalaron una retirada del estado nacional a partir de la entronización de la acción privada global en la regulación de la economía y desde esta lógica son evaluados procesos clave como la desregulación, flexibilización y privatizaciones que ocurren durante los '90 en la mayor parte de América Latina. En esta perspectiva explican que las redes transnacionales de distinto tipo escapan a todo control estatal y territorial: en esta línea se inscriben lecturas tecnológicas donde lo digital elimina el territorio y funciona con autonomía estatal.

Otros autores matizaron fuertemente esta afirmación y sostienen la importancia de territorios y estados, pues dentro de sus fronteras se desarrollan las actividades: se los requiere como soporte de su expansión. Saskia Sassen (1999) al analizar la reformulación de funciones estatales, hace hincapié en que lejos de retirarse, el estadonación sigue sosteniendo decisivamente las lógicas de reproducción del capital global. Se enfocan desde esta línea teórica nuevas y variadas tareas de negociación estatal nacional frente a las dinámicas económicas y los agentes económicos extranjeros, con lo que se amplía el debate:

“...desregulación, privatización o liberalización comercial y financiera son términos que describen ese proceso de negociación, pero el problema es que sólo reflejan la parte en que el Estado deja de regular la economía, sin registrar la forma en que va a 
participar en el nuevo marco que permite a la globalización avanzar" (Kuri, 2009, p. 63)

Desde esta mirada se subraya que los estados nacionales siguen siendo centrales para el funcionamiento de la economía, bien directamente o bien a través de gestionar:

“...el traspaso de funciones desde el gobierno nacional a instituciones privadas transnacionales, así como con el desarrollo al interior de los Estados nacionales de los mecanismos necesarios para asegurar los derechos del capital global" (Sassen, 1999, p. 159)

Basados en nuestro caso, el estado lejos de retirarse, sostiene de manera decisiva lógicas de expansión del capital global, a partir de sus instancias nacionales y subnacionales, ya que ocupa un lugar central y estratégico como articulador y/o gestor político que posibilita la instalación de CCs en sus respectivos territorios. No suscribimos una lectura de dichos estados como víctimas de la globalización, sino que la instalación de actividades económicas globales en territorios locales requiere que se ponga en marcha:

“...una combinación particular de leyes, reglamentos, alianzas políticas y acuerdos extraoficiales” (Sassen, 2010, pp. 13-14)

Las leyes, decretos, convenios y alianzas que regulan actividades económicas no son otra cosa que una objetivización del estado de una tensión siempre latente entre lógicas de mayor solidaridad y de beneficios colectivos de la sociedad y del territorio en su conjunto, frente a lógicas exclusivamente orientadas por la rentabilidad y los mayores beneficios individuales para los agentes económicos, en este caso las empresas de CCs.

\section{La regulación de la actividad económica: definiciones e impactos}

Abordamos un fenómeno de alto impacto social y económico. En efecto, cómo se regula un sector y con qué objetivos, incide no sólo sobre la actividad de dicho sector y quienes lo integran, sino sobre todo el territorio.

A nivel económico, los actores productivos reciben señales sobre qué sectores se van a priorizar en las estrategias de desarrollo estatales; además, los estados subnacionales se juegan su capacidad de mayor o menor financiamiento a partir de las ventajas impositivas que conceden.

A nivel social, se materializan procesos demográficos (capacidad de mayor retención de jóvenes en los territorios, por ejemplo), transformaciones socioocupacionales, emergencia de nuevos colectivos sociales, entre muchos otros impactos.

Pero antes de continuar cabe hacer referencia al término regulación. Según la OCDE:

"Las regulaciones son entendidas como el amplio rango de instrumentos legales y decisiones -constituciones, leyes parlamentarias, legislaciones subordinadas, decretos, ordenes, normas licencias, códigos y aún instrumentos informales-mediante los cuales los gobiernos establecen condiciones en la conducta de los ciudadanos, empresas y el gobierno mismo. Los sistemas regulatorios no solo comprenden reglas nacionales, sino 
también reglas desarrolladas por niveles subnacionales de gobierno, además de reglas desarrolladas en los procesos internacionales" ${ }^{\prime 3}$.

Si bien destacamos de esta definición la ampliación de la regulación a escalas sub y supranacionales, nos parece insuficiente: en los mecanismos regulatorios intervienen tanto gobiernos como empresas e instituciones sociales y su peso relativo es lo que hace que este conjunto de "reglas de juego" varíen según tiempo y lugar.

Desde esta perspectiva la regulación económica es producto de procesos sociales dinámicos, que determinan qué tipo de regulaciones son llevadas a cabo: no haremos nuestro análisis a partir de macro estructuras que regulan con un sentido lineal los destinos de nuestras sociedades; por el contrario, nos encontramos ante caminos sinuosos, con actores locales-nacionales-internacionales, del sector público y privado, con alianzas o enfrentamientos entre ambas partes, dependiendo de las circunstancias e intereses en disputa.

Desde esta perspectiva analizamos el rol de las instancias estatales subnacionales. Implica abordar un actor que ha alcanzado un mayor protagonismo en su capacidad de regulación sobre las economías locales, sumando funciones antes reservadas a los estados nacionales.

\section{La rearticulación de actores estatales y el auge de los estados subnacionales}

El concepto sasseniano de desensamblaje parcial de lo nacional explica la reformulación del estado-nación como centro institucional de donde emanaban derechos sobre todo el territorio como parte de un desplazamiento estructural dentro de una dinámica global que desestabiliza jerarquías escalares previas. La autora pone énfasis en que la capacidad transformadora de la dinámica de la globalización supone una imbricación profunda con lo nacional (con gobiernos, empresas, sistemas jurídicos, ciudadanía), es decir: no se impone uno sobre otro sino que son procesos interconectados y complementarios (Sassen, 2010).

Vayamos a observar cómo este concepto se aplica en el caso de la descentralización estatal ocurrida en Argentina, para luego entenderlo como una de las formas de insertarse globalmente, que implica desplazamientos estatales. Uno de los principales estudiosos del funcionamiento estatal argentino observa que:

"La descentralización ha creado la ilusión que la burocracia estatal se ha reducido. Sumados sus efectos a los de privatización, desregulación y tercerización de servicios es evidente que el tamaño de la dotación del estado nacional se ha reducido. Pero junto con ello, las burocracias subnacionales han visto abultadas sus dotaciones a extremos que no se compadecen con el volumen de servicios transferidos" (Oszlak, 1997, p. 21)

En el mismo sentido, Pablo Ciccollela (1996) subraya que en general la descentralización ha servido para profundizar y bajar el ajuste hacia las regiones y/o provincias, ya que se descentralizaron atribuciones, responsabilidades y funciones, sin descentralizar recursos proporcionalmente. Sin embargo ello también ha generado que frente a la mayor debilidad relativa del Estado-Nación:

\footnotetext{
${ }^{3}$ Véase OCDE, The OECD report on regulatory reform, Paris, 1997, vol. II, p. 196.
} 
“...las regiones o unidades territoriales subnacionales han ganado importantes espacios de poder vía descentralización de funciones administrativas y tienden a vincularse o insertarse en la nueva división territorial global del trabajo de una manera más directa, con menos mediaciones de parte del Estado Nacional" (Ciccollela, 1996, p. 48)

A partir de la transferencia a terceros (al mercado, a los gobiernos subnacionales) de muchas de las responsabilidades que antes asumía como propias el estado nacional, de su achicamiento cuantitativo en recursos y de la reformulación de tareas que asume, se produce entonces un avance condicionado de instancias estatales subnacionales, pero con estrechos márgenes de acción.

Poder observar esta compleja dinámica a partir de la actividad de CCs nos parece pertinente en tanto permite observar cómo los estados subnacionales se posicionan frente a un agente económico de notable crecimiento, liderado por empresas transnacionales (de alcance global en cuanto a clientes y proveedores con los que interactúan), con posibilidades tecnológicas de deslocalización de capitales y con peso en el territorio como generador de empleo intensivo, pero -a partir de aquello- también como actor político con capacidad de lobby sobre las formas de regulación ejercidas.

\section{LOS ACTORES ESTATALES Y LA EXPANSIÓN DE LA ACTIVIDAD DE CCS EN ARGENTINA}

\section{Historia y presente del rol estatal}

En los comienzos de los años '90 en Argentina se había de un diagnóstico que insistía en que la economía estaba trabada por una relación inadecuada entre el Estado y el mercado. Aquel se había involucrado con escasa eficacia en actividades productivas propias del sector privado y éste se había acomodado a la situación desarrollando una serie de comportamientos poco competitivos. Económicamente, con un caos hiperinflacionario de fondo, el gobierno recién electo de Menem pone en práctica medidas estructurales que, en conjunto, modifican la estructura y funciones estatales y que se plasmaron en la Ley de Emergencia Económica y Ley de Reforma del Estado 4. Estas medidas, junto a otras de menor impacto, produjeron lo que se denominó por varios autores la retirada del Estado, denominación poco feliz pues en realidad lo que se produjo fue una reorientación de las funciones estatales 5 .

\footnotetext{
${ }^{4}$ Se sanciona la Ley de Emergencia Económica, que suspendía por 180 días -luego sería renovado indefinidamente- los regímenes de promoción industrial, regional y subsidios a la exportación, así como se suspenden los beneficios para las manufacturas nacionales en las compras del Estado. La Ley de Reforma del Estado fija el marco normativo para la privatización de numerosas empresas públicas.

${ }^{5}$ Respecto a sus consecuencias, véase Schorr (2002). Las conclusiones principales a las que arriba el autor son que la retirada del Estado operada en los '90 en Argentina (plasmado en las privatizaciones, la desregulación de numerosos sectores de actividad y la apertura económica asimétrica) fortaleció a actores con poder dominante en el mercado, permitiendo prácticas oligopólicas predatorias de esos actores que perjudican la progresiva distribución del ingreso. En definitiva, el slogan neoliberal pregonado "más mercado y menos Estado" no es siempre aplicado: durante el menemismo el desguace estatal generado especialmente por las privatizaciones generó menos Estado, pero no más mercado: no se inyectó competencia al mercado, sino que se mono u oligopolizaron economías en las áreas más rentables, y sólo algunas -en gran parte las áreas donde más actuaban las Pymes- fueron desreguladas.
} 
Contrariamente a esta imagen de retirada estatal, en el fenómeno aquí investigado sostenemos que el estado nacional ha tenido responsabilidades indudables en la instalación y reproducción de este nuevo agente económico que es en su conjunto la actividad de CCs.

Ilustremos concretamente esta afirmación.

En una primera etapa, en la segunda mitad de los '90 la acción del estado nacional posibilita el crecimiento de CCs nacionales y la entrada de empresas extranjeras en nuestro país a partir de varios factores:

a) la privatización del servicio de telecomunicaciones y posterior desregulación del sistema de las telecomunicaciones de larga distancia y de telefonía celular;

b) con el dictado de marcos regulatorios que homologan reglamentaciones y normas de calidad que rigen a escala global;

c) con el impulso para la descentralización de tareas de legislación tributaria ahora operadas directamente desde estados subnacionales que permiten agilizar mecanismos de captación de capitales;

d) con inversión pública en infraestructura tecnológica, servicios, recursos humanos, etc.

En cuanto a su regulación, la actividad de CCs ya está contemplada o al menos tiene su base -que luego puede adaptarse- en la legislación nacional: se puede hacer referencia a la ley nro. 24.240 conocida como Ley de Defensa al Consumidor que otorga gran impulso a la demanda en servicios de CCs entre las grandes empresas que deben garantizar los derechos al consumidor al comprar un bien o servicio (muchos instalan el famoso 0-800); también la ley nro. 25.326 o Ley de Habeas Data, que contiene regulación sobre la protección de los datos personales (los CCs son genéricamente centros de almacenamiento de información de clientes, si no existiese esta ley difícilmente los CCs podrían funcionar).

En esta primera etapa, como se ha detallado, se sancionan las leyes que enmarcan y permiten funcionar a la actividad, que aún no está hegemónicamente transnacionalizada y se orienta esencialmente a cubrir la demanda del mercado local.

En base a la coyuntura económica iniciada el año 2002 se observa una marcada tendencia a la deslocalización de servicios, extranjerización y alta concentración de los CCs. En un estudio reciente se detalla que menos de diez empresas concentran las operaciones del mercado local, mientras que las cinco empresas líderes del sector son subsidiarias de grupos multinacionales (del Bono y Henry, 2009).

Más adelante, al mantener un tipo de cambio alto se ha beneficiado ampliamente a CCs multinacionales exportadores: así termina de instalar un nuevo agente económico.

En esta segunda etapa (posdevaluación), con un sector más consolidado, los estados subnacionales son los que lideran las estrategias regulatorias y orientan sus funciones para atraer CCs a través de leyes- decretos-convenios que incluyen exenciones impositivas, donación de infraestructura edilicia, subsidios a salarios, capacitación de personal costeada por el estado, bonificación de cargas laborales, aportes para equipamiento y oficinas, entre otras ventajas: ello acelera la instalación de CCs en Argentina.

6 Se legisla "a medida" de compañías extranjeras privadas de telecomunicaciones que producen inicialmente una enorme demanda de CCs. 


\section{Los agentes económicos y sus demandas hacia los estados}

La creciente dinámica global de la actividad de CCs y sus características inherentes que facilitan su deslocalización ${ }^{7}$ nos lleva a indagar sobre las capacidades de los estados en el marco de una economía global. Cabe decir que las grandes empresas multinacionales son las que lideran el crecimiento de este negocio y, articulados internacionalmente, han tercerizado en gran medida la tarea de servicios de CCs. La estrategia de las empresas transnacionales es doble: por un lado se orientan hacia la exportación de servicios $^{8}$, autonomizándose respecto a la evolución de la demanda y del crecimiento de la economía local en donde instalan sus plataformas. Por otro lado, con la reciente crisis financiera mundial se ha puesto al descubierto un segundo tipo de comportamiento empresarial: se han observado nuevas estrategias de las empresas multinacionales que adquieren firmas locales (líderes en el mercado doméstico) para cubrir el mercado interno, que opera con mayor dinamismo que el extranjero, al tiempo que buscan trasladar el aumento de los costos laborales a los precios.

Estas características y su lógica de funcionamiento han hecho que las empresas de CCs -especialmente por ser mano de obra intensivas- tengan peso como agentes económicos con capacidad para visibilizar e imponer demandas, es decir tienen voz y peso político donde se instalan ${ }^{9}$. Su brazo político son las cámaras empresariales, desde donde interpelan a los estados nacionales y subnacionales. La amenaza de relocalización de CCs ya radicados y pérdida de nuevas inversiones se agita en revistas especializadas y congresos empresarios (se alude a una supuesta hipermovilidad de CCs sin sujeción al espacio físico, reduccionismo tecnológico que invisibiliza el factor local ${ }^{10}$ ).

La presión discursiva hacia instancias estatales pondera la mayor competitividad de otros países o provincias, y opera como pedido de menores costos laborales y mayores ventajas fiscales compensatorias. La apelación a las instancias estatales opera en dos

7 Gracias a la posibilitad de fragmentar la cadena de producción empresas de países centrales exportan actividades de baja jerarquía intensiva en mano de obra (Según la consultora Convergencia Research actualmente se calculan cerca de 70.000 empleados en CCs tercerizados, a eso habría que agregarle alrededor de 50.000 empleados en CCs in-house, es decir, operados por la propia compañía).

8 En 2009 es Europa el principal lugar de exportación con 55\% del negocio, seguido de EEUU con 33\% y América Latina con 9\% (Fuente: Agrupación Centros At. al Cliente de Cámara Argentina de Comercio). Para observar su magnitud, en 2008 Convergencia Research muestra que en Argentina la facturación de CCs rondó los 2 mil millones de pesos; sobre dicha facturación un 33\% correspondió a exportación.

9 Las cámaras empresariales difunden habitualmente frente a gobiernos y opinión pública los siguientes beneficiosos que CCs traerían a territorios locales: empleabilidad (posibilidad de primer empleo para jóvenes, absorción de empleo femenino), capacitación, trabajo en blanco, etc.

10 Esta presión se asienta en un supuesto de acumulación económica global de mayor alcance: los bienes intangibles (dinero, información) son los que más fácilmente se desplazan a nivel mundial y si no hay políticas estatales que ofrezcan alta rentabilidad pueden emigrar a otras latitudes. Sin embargo, para el caso de los CCs tienen un importante valor factores locales, especialmente para la cobertura de ciertos mercados: por ejemplo, para el mercado de EEUU o España es necesario ciertas competencias (modales internalizados culturalmente, comprensión idiomática plena), así como un huso horario adecuado al suyo, como se ofrecen en Argentina. En este sentido, una funcionaria del gobierno de la ciudad de Bs. As., del área del Centro de Atención al Inversor (Ministerio Desarrollo Económico) nos comenta "Pasa que Bs As, es un lugar estratégico, por la zona horaria...el otro lugar estratégico es India, pero el nivel cultural no es tan bueno como el de acá. Entonces la mayoría están, muchas empresas están diciendo 'Bueno, prefiero poner más plata, prefiero pagar más a los empleados, pero tener mejor servicio'”. 
escalas. Frente al estado nacional se demanda equiparar las ventajas fiscales de otros países latinoamericanos y son habituales entre los ejecutivos frases como la que sigue:

"Cuando tenés gobiernos que alientan la industria de Perú y Colombia que compiten con nosotros en offshore fundamentalmente a España, a la industria le quedan pocas herramientas porque no maneja el tipo de cambio, ni las regulaciones, ni los subsidios $" 11$

Mientras que frente a los estados subnacionales se mencionan los beneficios otorgados por otras provincias argentinas. Habitualmente en los discursos se apela a "casos de éxito" como el que sigue:

“...hasta el momento hemos logrado, por ejemplo, que en la provincia de Tucumán entiendan claramente de lo que es capaz el sector; de que en Córdoba sigan, de alguna manera, algunas exenciones impositivas ",12

En ambos casos, la demanda hacia el estado es que intervenga "a medida", es decir, que oriente sus acciones y recursos a reducir costos fiscales y laborales. Veamos cuáles han sido las acciones regulatorias específicas de los estados subnacionales hacia la actividad.

\section{LA REGULACION DE LOS ESTADOS SUBNACIONALES HACIA LA ACTIVIDAD DE CCs}

En los últimos años se ha generado un efecto cascada entre provincias en cuanto a legislación sancionada hacia la actividad. En efecto, ininterrumpidamente año tras año en el último lustro se suman nuevos territorios que brindan beneficios a las empresas de CCs para que allí se instalen.

Sistematizamos en la figura 1 y el cuadro 1 que siguen a continuación, los territorios principales donde se ofrecen regulaciones beneficiosas para la instalación $y$ funcionamiento de la actividad de CCs. Si bien en otros territorios existe legislación que beneficia a la actividad, no es tan específica hacia los CCs (se adapta legislación más amplia para cubrir sus demandas) o bien se está negociando en la actualidad su sanción ${ }^{13}$.

\footnotetext{
11 Frase extraída de informe de José Romero Victorica, Presidente del CC Allus Global y Fundador de Cámara Empresaria de Servicios y Contactos para Terceros en Córdoba (CESCT). Disponible: $<$ http://www.siicex.gob.pe/siicex/resources/sectoresproductivos/Presentaci\%C3\%B3n_PromPeru__ALLUS_2009.pdf $>$ [2 de febrero de 2011].

12 Frase que se extrajo de una entrevista en la Revista Contact Center a Fernando Padrón, Presidente del CC ActioLine. Disponible: <http://www.contactcentersonline.com/revista.php?IdRevista=143>. [21 de marzo de 2011].

13 En la provincia de Bs As los CCs se benefician de la ley 13.656 de Promoción Industrial. Por su parte, en Santa Fe, con varias idas y vueltas, se han enviado proyectos a la legislatura desde el año 2006 en la gestión del gobernador Obeid, pero en ningún caso ha prosperado regulación específica para los CCs.
} 
Figura 1. Año y territorio donde se han sancionado las principales leyes, decretos y convenios reguladores de la actividad de CCs

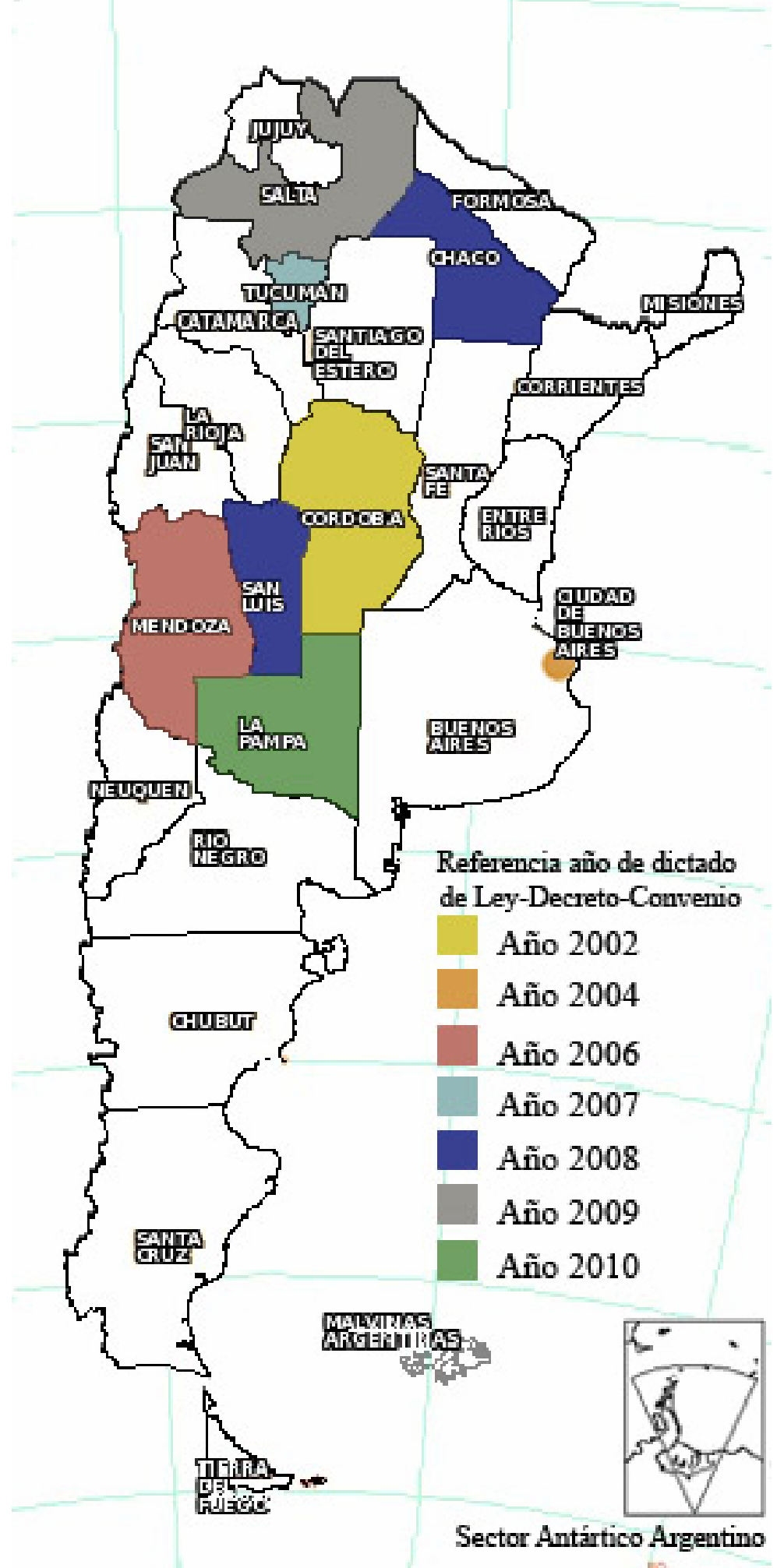

Fuente: Elaboración propia. 
Como se observa en el Gráfico 1, se comienza ofreciendo beneficios a los CCs (a través de leyes, convenios, decretos) en Córdoba y la Ciudad Autónoma de Bs. As. (CABA); esto se produce en los comienzos de la devaluación o inmediatamente después. En el último lustro (del año 2006 en adelante) se han sumado aceleradamente varias provincias a sancionar leyes-decretos-convenios que benefician a la actividad de CCs.

Cuadro 1. Detalle de los principales beneficios obtenidos por los CCs para su instalación en los territorios argentinos

\begin{tabular}{|c|c|c|c|c|c|c|c|c|}
\hline 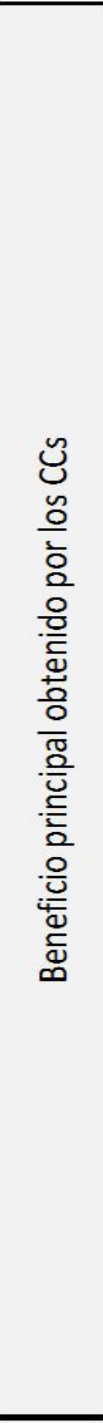 & 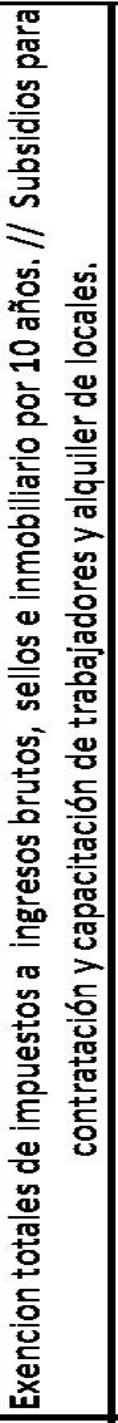 & 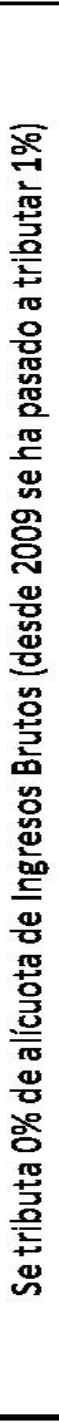 & 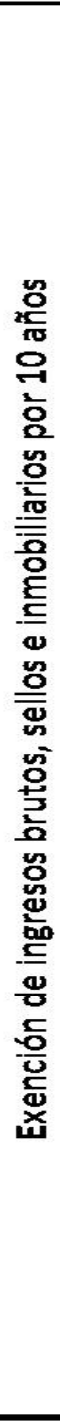 & 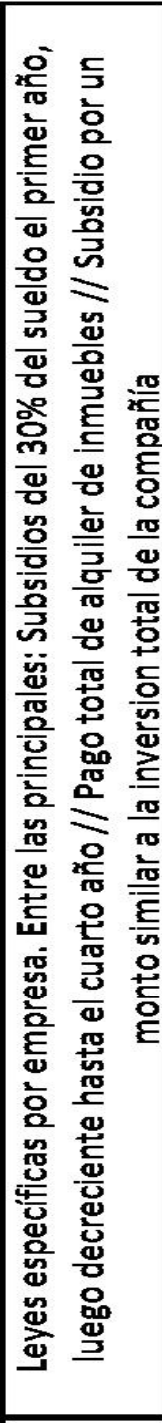 & 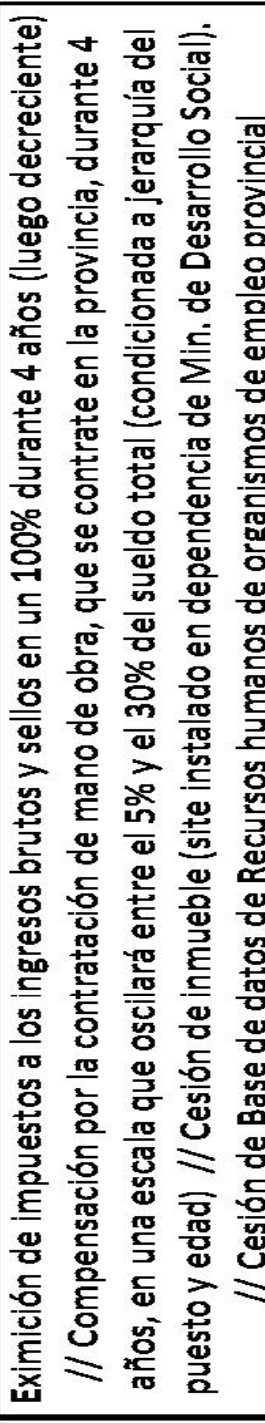 & 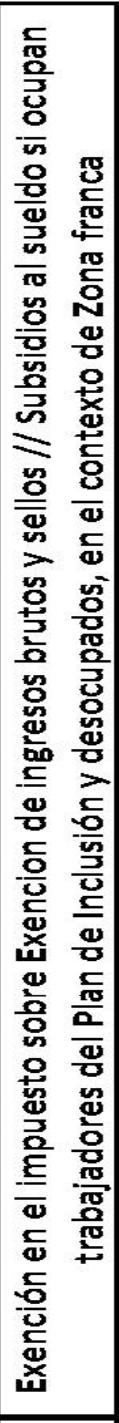 & 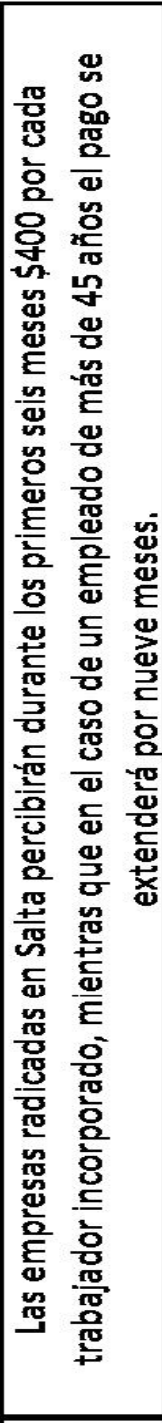 & 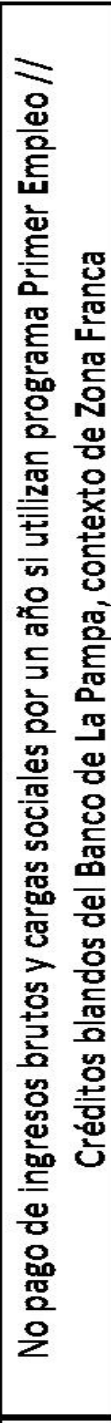 \\
\hline 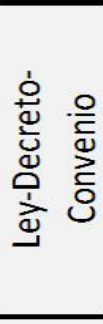 & 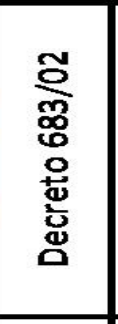 & 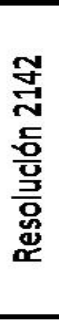 & 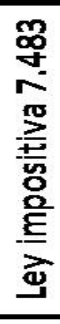 & 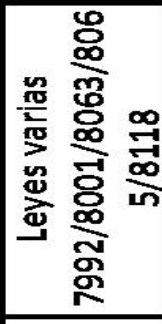 & 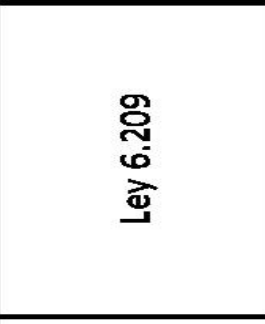 & 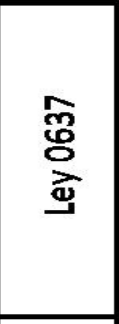 & 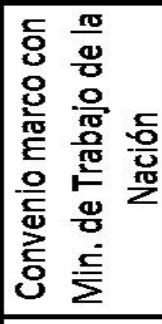 & 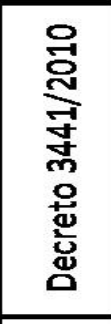 \\
\hline 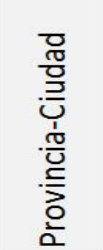 & $\begin{array}{l}\text { 응 } \\
\text { 응 }\end{array}$ & 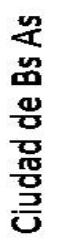 & 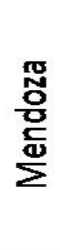 & $\stackrel{\text { 를 }}{\mathrm{g}}$ & 总 & 忍 & & \\
\hline
\end{tabular}

Fuente: Elaboración propia. 
Como se describe en el Cuadro 1, se otorgan: por un lado tipos de beneficios similares al resto de las provincias (en el análisis de los debates parlamentarios se observa sistemáticamente que se utiliza legislación ya sancionada en otros territorios nacionales). Respecto específicamente a los beneficios impositivos, se destaca el impacto de la exención de ingresos brutos en la mayor rentabilidad de las empresas ${ }^{14}$.

Por otro lado, cada uno de los territorios ofrece beneficios que se ajustan a la historia y funcionamiento estatal local (por ejemplo San Luis otorga beneficios impositivos a CCs a condición de que éstos tomen mano de obra incluida en sus planes laborales; o Chaco, con una fuerte impronta estatal, ofrece seleccionar al personal de CCs).

\section{Figura 2. Evolución de la cantidad absoluta (en miles) de empleados de CCs tercerizadores en el período 2003-2010, según territorio}

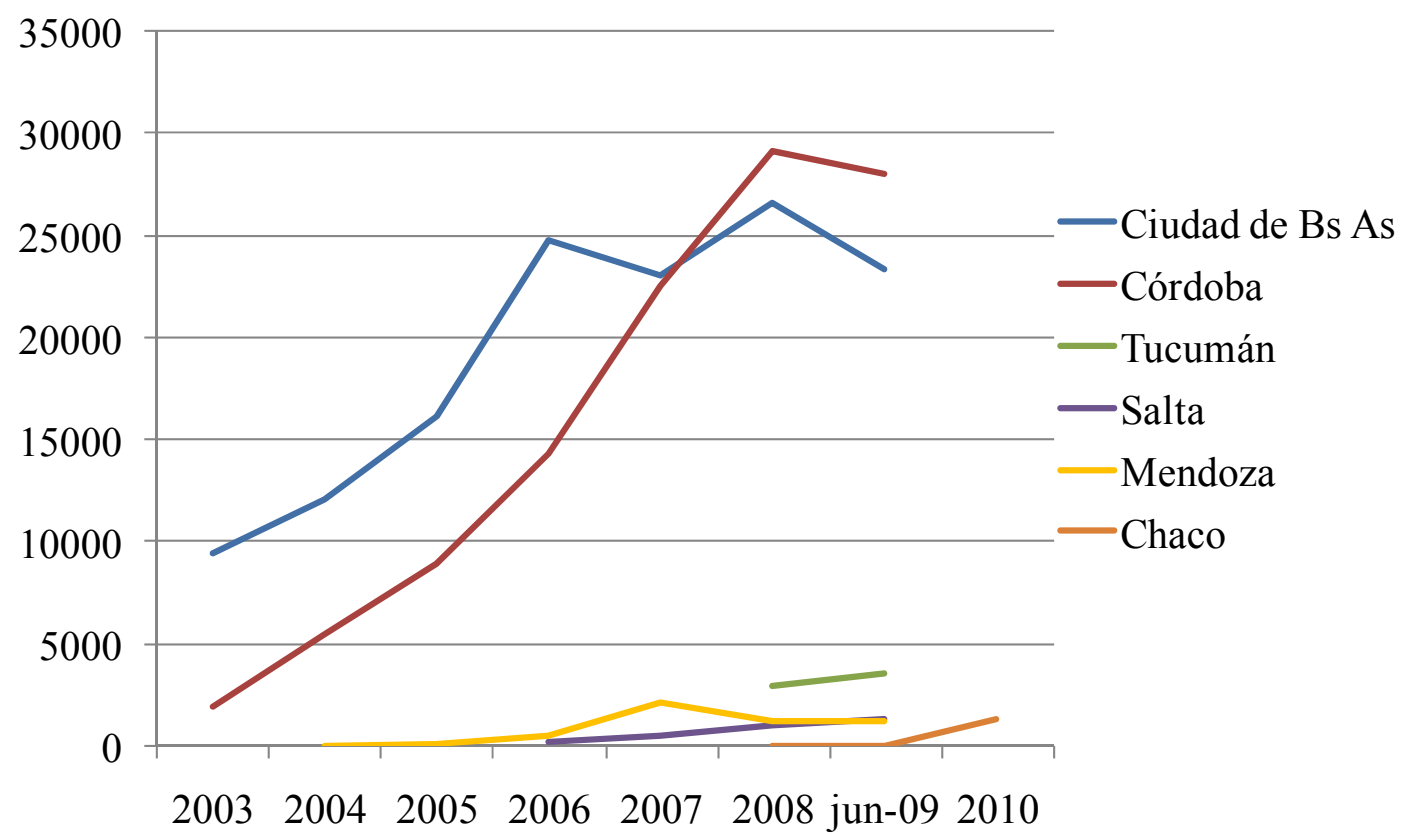

Fuente: Agrupación Centros de Atención al Cliente de Cámara Argentina de Comercio y datos propios. Elaboración propia

\footnotetext{
${ }^{14}$ Respecto al impacto que generan para los CCs las exenciones impositivas, nos comenta un gerente de Administración y Finanzas de un CC mediano (alrededor de 800 empleados) ubicado en la ciudad de Bs. As.: "...la ciudad de Bs As en su momento hizo un gran esfuerzo. En realidad lo había hecho en su momento, y después fue un poquito menos: en un momento habian exceptuado Ingresos Brutos para la actividad de call center y ahora está gravada al 1\%. Y hay mucha diferencia, porque es un servicio de tanto valor agregado éste, que vos facturas una diferencia muy grande: un punto de Ingresos Brutos es mucha plata para una PYME como nosotros". En este sentido y respecto al peso de este tributo para la rentabilidad del CC, una funcionaria del gobierno local en la ciudad de Bs. As., del área del Centro de Atención al Inversor (Ministerio de Desarrollo Económico) nos comenta: “...15 años de exención impositiva, no contemos ni ABL ni sellos, digamos que no es tan relevante numéricamente como ingresos brutos. Pero solamente ingresos brutos ya le genera a la empresa un ahorro increíble y la posibilidad de capitalizar".
} 
Finalmente, en la Figura 2 se destaca que existe una alta correlación entre estos beneficios otorgados por los estados subnacionales y la generación de empleo en los territorios, consecuencia de la instalación espacial de los CCs allí ${ }^{15}$.

Los dos principales territorios donde generan empleo los CCs son Córdoba y CABA. Son justamente las jurisdicciones donde primero se comienza a legislar para atraer las inversiones en CCs.

Sin embargo, en los últimos años (desde 2008 en adelante) estos territorios muestran una pérdida de empleo absoluto, mientras que en jurisdicciones más pequeñas como Tucumán, Salta y Chaco se comienza a observar un crecimiento en la generación de empleo. Esta tendencia coincide con la sanción de leyes en estos últimos territorios.

Un caso intermedio es el de Mendoza: se observa un pico de empleo en el año 2007 (en el año 2006 se había sancionado la ley impositiva 7483); luego decrece el empleo.

El peso de los beneficios otorgados y la dinámica de competencia que se ha generado se observa en mayor medida en el interior del país: a la localización que las nuevas inversiones en CCs realizan, que tienden a instalarse en los territorios que les ofrecen más importantes beneficios, se suma lo que algunos autores ya han conceptualizado como procesos de deslocalización entre provincias a partir de una verdadera competencia de "facilidades" (Garro, 2008).

Vayamos a observar cómo ha sido esta relación estado/CCs en el territorio que actualmente tiene la mayor cantidad de empleo generado por CCs tercerizadores en todo el país, esto es, la provincia de Córdoba.

\section{El rol estatal en la provincia de Córdoba}

Si bien operaban en Córdoba algunos CCs antes del año 2002, la masividad del servicio se acelera luego de la devaluación. La baja de costos laborales y una legislación que otorga exenciones impositivas y seguridad jurídica -imitada por varias provincias- son pilares para la llegada de nuevos CCs. A diferencia de otras provincias suma como factor de localización un entrelazamiento fluido de redes productivas y actores políticosociales aliados en pos del objetivo de radicación de este tipo de empresas. Esta alianza $^{16}$ y la alta dotación de mano de obra universitaria, logra posicionar a la provincia como el principal empleador del país en CCs. Actualmente las principales empresas instaladas en Córdoba son de capitales multinacionales - conviven con CCs nacionales de menor envergadura-.

En el año 2001, dentro de un programa de fomento a la creación de un polo tecnológico que otorga regímenes de promoción industrial para radicación de industrias tecnológicas y desarrollo de software, se incluye a los CCs como parte de este polo (mediante la

15 Se han graficado territorios donde existe importante legislación que ha beneficiado en el período a los CCs. Esto excluye a la provincia de Bs. As. y Santa Fé que -en relación al resto de los territorios- han otorgado menores beneficios. En ellos el empleo ha permanecido relativamente estable o ha crecido, pero más producto de su expansión inicial donde pesaba más el costo laboral bajo e instalarse en grandes metrópolis, que una ley en particular. En las provincias de San Luis y La Pampa surge el empleo en CCs luego de otorgados beneficios hacia la actividad: no se han graficado por su escaso valor absoluto, lo que dificulta su visualización.

16 Alianza observada recurrentemente en congresos empresariales declarados de interés provincial y con asistencia habitual de funcionarios públicos de alto rango. 
eficaz presión ejercida por cámaras empresariales de CCs y la rápida asistencia del estado provincial) inicialmente pensado para recibir empresas de software y electrónica.

En el año 2002 el ex gobernador De la Sota promulga el decreto 683/02: el decreto permite agilizar la instalación de los CCs en la provincia, evitando los tiempos más lentos del debate parlamentario. Luego, en el año 2005, la legislatura provincial sanciona la ley nro. 9232 (basado casi textualmente en el decreto previo) que en la práctica da mayor seguridad jurídica a empresas, ya que la ley no puede ser modificada fácilmente por gobiernos de turno. Dicha ley otorga exenciones totales del pago de impuestos sobre ingresos brutos, sellos e inmobiliario por un plazo de diez años; y otorga subsidios para alquiler de locales y para contratar y capacitar empleados.

En el debate parlamentario del año 2005 se observan posiciones políticas en pugna. El proyecto de ley -enviado por el bloque oficialista Unión por Córdoba- en su fundamento sostiene:

"La concentración de actividades de las citadas corporaciones en nuestra Provincia, permitirá beneficios a clientes, oportunidades laborales dirigidas especialmente para jóvenes universitarios y acceso al mercado internacional, generándose exportaciones de servicios no tradicionales" $" 17$

Varios bloques opositores cuestionan el proyecto, desde diferentes ángulos:

1) críticas por su nula integración comunitaria provincial

"Nos hubiera gustado que esta eximición fuera a cambio de alguna contraprestación, como otrora cuando se le daba eximición a las empresas automotrices. Si estas empresas que van a ser beneficiadas, o que ya cuentan con el beneficio dado por decreto, estuvieran invirtiendo en educación, en cultura, en asistencia social a nuestra comunidad, si estuvieran dando algún tipo de beneficios o servicios gratuitos a nuestra provincia quizás podríamos haber acompañado este proyecto” (Bloque UCR)

2) críticas hacia la concepción de polo tecnológico que plantea el proyecto

“... el Secretario de Industria comentó el antecedente de Irlanda, pero no se corresponde con la verdad. En Irlanda se desarrolló el software y hardware a partir del apoyo de la Comunidad Económica Europea con cuantiosos fondos que fueron destinados a Irlanda como zona desfavorable y capitales provenientes de EEUU. Radicaron capital genuino para inversión en estos sectores, acompañado con los servicios; no se crearon los servicios para que después surgieran las otras empresa" (Bloque Frente Nuevo)

3) críticas por el trabajo precarizado y la inserción en el mundo que propone:

"nos queda el sabor amargo de tener que tragarnos el cuento de la generación de puestos de trabajo, cuando lo que estamos generando es esclavitud laboral a corto y largo plazo. Están apoyando el trabajo golondrina. Es muy probable que el negocio se

17 Este fragmento y los más abajo expuestos fueron extraídos del Diarios de Sesiones de la $14^{\mathrm{a}}$

Reunión - $12^{\circ}$ Sesión Ordinaria del Poder Legislativo de la Provincia de Córdoba del 13 de Abril de 2005, pp. 710-721. Disponibles: <http://www.legiscba.gov.ar/info_sesiones.asp>. [2 de marzo de 2011]. 
traslade a otro punto del planeta cuando todo esté listo para cosechar los frutos de la inversión” (Bloque Izquierda Unida).

4) críticas institucionales del funcionamiento de los órganos estatales:

"se está convirtiendo a esta Legislatura en una dependencia más del Poder Ejecutivo al pretender convalidar por la vía legislativa un decreto” (Bloque Recrear).

En respuesta a las críticas, el legislador Massei -coautor del proyecto- declara:

"Gobernar es crear trabajo y condiciones para generar empleo" y seguidamente:

"El nuevo federalismo argentino será indudablemente la disputa entre las distintas regiones del país, y aquellas empresas o noveles empresas que no se radiquen en esta provincia indudablemente escogerán otro destino”. Finaliza su alocución sosteniendo:

“...en esta Legislatura se ha hablado a lo mejor pensando que estábamos en la Bélgica o Francia de la Unión Europea”.

Es interesante observar en estos fragmentos de los debates políticos lo que esta relación estados/CCs ha instalado en las legislaturas, pues otorga mayor sentido a la comprensión de lo ya objetivado en ley. En otras palabras: ¿qué nuevas realidades estamos discutiendo al abordar la regulación hacia la actividad de CCs? ¿cuáles son los límites y potencialidades de los estados subnacionales en esta nueva realidad?

Las dimensiones más relevantes de los debates políticos en torno a la legislación hacia la actividad $^{18}$ que se visibilizan son:

a) la vinculación global/local: los fragmentos transcriptos revelan los límites de los espacios locales en la conexión con lo global. Si bien se observa como una posibilidad cierta la instalación de empresas transnacionales en el territorio, ello podrá generar empleo pero "no somos Bélgica o Francia". En esta declaración -del propio autor del proyecto- se desliza una mirada de resignación a los dictados de las inversiones globales, sin poder de control o soberanía plena sobre ellos, lo que habla de una inserción global/local endeble para el territorio.

b) la intercompetitividad territorial: se explicita una nueva dinámica de competitividad interterritorial. Sin la intervención del estado nacional, cada territorio debe lograr atraer las inversiones globales. Ligado a ello se puede mencionar como subdimensión la velocidad de actuación estatal, ya que se ha observado que la rapidez en la sanción de leyes u otros tipos de beneficios para los CCs es un atributo esencial para que esas inversiones lleguen a los territorios. En algunos casos, esta imposición de mayor velocidad redunda en rearticulaciones de la relación de las legislaturas provinciales y los poderes ejecutivos locales, donde en ocasiones se imponen la velocidad del decreto

18 Se debe destacar que la instalación de CCs ha generado también un debate de tipo jurídico que aquí no se profundiza, acerca de cambios en el código fiscal para adaptarse a las nuevas actividades económicas (véase Curcio, 2005). Sin menospreciar este debate, creemos que lo decisivo aquí, más que los criterios de equidad tributaria, es indagar acerca de las posibilidades de desarrollo para los territorios con la llegada de los CCs, temática que se aborda en un debate de tipo político y no jurídico. 
dictado por el ejecutivo frente a los tiempos significativamente mayores del trámite parlamentario y la sanción de la ley.

c) las estrategias de desarrollo posibles: se debate en torno al valor para el desarrollo que los CCs generan en los territorios, tanto en sus características de externalidades productivas como en la calificación de la mano de obra necesaria y la relación con la comunidad establecida. En cada uno de estos puntos las críticas apuntan a la fragilidad de la actividad en tanto no generan polos tecnológicos de desarrollo, ofrecen trabajo precarizado y no establecen un vínculo con la comunidad local traducido en inversión en educación, cultura o asistencia social. Quienes defienden el proyecto apuntan a los atributos de los CCs en tanto absorben rápidamente mano de obra local de manera intensiva.

Si bien cada dimensión se enuncia separadamente para una mejor comprensión de cada una de ellas, se debe resaltar que están profundamente imbricadas unas con otras. En conjunto, configuran en toda su complejidad el fenómeno que estudiamos, en tanto visibilizan todo lo que subyace a la lógica de localización de los CCs, esto es, el desarrollo no sólo de nuevas relaciones entre Argentina y el mundo, sino también entre los propios territorios nacionales internos.

\section{ALGUNAS REFLEXIONES FINALES}

La globalización económica ha provocado nuevas (re)articulaciones nacionales entre los actores estatales y extraestatales a nivel mundial. En este contexto, los estados deben "aprender el arte de navegar en los flujos" (Castells, 1998).

Cada territorio ha tenido que procesar estas transformaciones y ha tenido que ser capaz de gestionar una realidad más compleja, aunque cada uno de ellos lo ha hecho de formas diversas. En este marco, sus estructuras y funciones estatales han mutado teniendo en cuenta su propio funcionamiento previo. En efecto, los estados se transforman, pero no lo hacen desde el llano: se debe tener en cuenta que lo hacen desde una sedimentación en tareas, funciones e interrelaciones que han llevado adelante a lo largo de toda su historia.

No estamos ante la presencia de una refundación de los estados, pero sí ante una reformulación de los mismos que ha traído como consecuencia nuevas reglas de juego con los diversos actores sociales, con otras instancias estatales, con agentes económicos y con su propia comunidad.

Entre las transformaciones estatales, una de las más significativas es la rearticulación de las instancias estatales nacionales y subnacionales en torno a la regulación de las actividades económicas de matriz global. Los estados nacionales conservan importantes funciones para que lo global pueda insertarse en lo local, mientras delegan otras tareas -quizás de mayor visibilidad- en los estados subnacionales. Así se produce una regulación combinada de las actividades económicas, donde ambas instancias conservan grados de autoridad y capacidad institucional para tomar e imponer decisiones. Sin embargo debemos comprender que también los agentes económicos transnacionales han impuesto sus propias capacidades y han obligado a redefinir nuevos poderes compartidos. 
Esta nueva forma de gestión no está exenta de asimetrías. Una de ellas se puede visualizar al observar las acciones de los estados subnacionales para fomentar la instalación de ciertas actividades económicas, que si bien demuestra ser una forma ágil y exitosa de atraerlas, lejos está de poder captar actividades de mayor valor agregado para el territorio o de imponer condiciones más favorables para el desarrollo de los mismos.

Esta rol de los estados subnacionales se visibiliza claramente frente a la localización de CCs en Argentina, pues allí donde se instala un CC, existe la intervención estatal como facilitador de su llegada. Al captar estas inversiones, se hace visible un estado a la defensiva, que cede a grandes empresas multinacionales el liderazgo del proceso en las condiciones de instalación. Se observa una lucha desigual: la de estados subnacionales o aún municipales- frente a agentes económicos cada vez más concentrados y transnacionalizados.

En Argentina, no se ha logrado la coordinación necesaria entre los estados nacionales y subnacionales que pueda enfrentar con mejores resultados a estos agentes económicos y ello ha debilitado el poder de negociación territorial. En otras palabras, enfrentamos nuevas relaciones entre Argentina y el mundo globalizado de manera más atomizada. En tanto el estado nacional ya no se encarga de ciertas funciones de orientación y control sobre los capitales foráneos, los estados subnacionales compiten descarnadamente por captarlos: esta nueva realidad enfrenta a los territorios locales. La lógica que guía estas disputas es la de ser territorios "competitivos".

En este contexto y desde la perspectiva que hemos intentado enunciar y objetivar en este trabajo, esto es, la de integrar en el análisis la historia de las instancias estatales junto a los desafíos del presente, creemos que permiten comprender mejor el rol estatal en torno a la llegada de CCs en Argentina.

Por ejemplo, el caso de la provincia de Córdoba es ilustrativo de esta imbricación con su propia historia estatal y socioeconómica: con una estructura productiva de magnitud y mayor desarrollo de agentes económicos privados, allí la conformación de la Cámara empresarial de CCs ha tenido fuerte influencia en la llegada de estas inversiones a la provincia y allí el estado muy tempranamente se ha aliado y ha potenciado la iniciativa privada.

Quizás un buen ejemplo en el otro extremo de funcionamiento, sean las acciones del estado provincial chaqueño, que al intentar captar estas inversiones ofrece servicios a los CCs a priori asociados al ámbito privado como la cesión de bases de datos o realizar la selección de personal para el CC (tareas habitualmente realizadas por empresas privadas de recursos humanos). En el territorio chaqueño, a lo largo de su historia la iniciativa privada ha sido débil, y al no poseer una estructura productiva de magnitud que se suma a los altos índices de pobreza y marginalidad que presenta, todas las carencias se han suplido (o se han intentado suplir) con una fuerte iniciativa estatal provincial.

En otros estudios (véase Moench, 2011) hemos detallado la baja generación de cadenas de valor agregado locales, la escasa creación de eslabonamientos productivos y el trabajo precarizado que la actividad de CCs promueve en los territorios -al menos en la mayoría de los servicios que se brindan desde Argentina-, por lo que habría que replantear las políticas públicas hacia el sector. 
Esperamos con este trabajo esclarecer y sistematizar qué ventajas han obtenido las empresas de CCs en Argentina y alentar la intervención del estado nacional en el control y orientación de los flujos de estas inversiones. Finalmente, también nos gustaría contribuir a otorgar mayores márgenes de poder de negociación hacia los estados subnacionales.

\section{BIBLIOGRAFÍA}

BENKO, G. y LIPIETZ A. De la regulación de los espacios a los espacios de regulación. Documento de Investigación Nro 50. Paris: Centro de Recherche sur L'Industrie et L'Amenagement, Instituto de Geografía de Paris, 1994.

BORJA, J. y CASTELLS, M. Local y global. La gestión de las ciudades en la era de la información. Madrid: Ed. Taurus, 1997.

CASTELLS, M. ¿Hacia el estado red? Globalización económica e instituciones políticas en la era de la información. Ponencia presentada en el Seminario sobre Sociedad y reforma del estado" en Sao Paulo, organizado por el Min. de Administracao Federal e Reforma Do Estado, 1998.

CICCOLLELA, P. Reestructuración global, transformaciones económicas en la Argentina y reterritorialización de la región metropolitana de Buenos Aires. Hacia una ciudad competitiva, globalizada y excluyente. Revista de Estudios Regionales, Nro. 43 pp 45-68, 1996.

CORIAT, B. Los desafios de la competitividad. Bs. As.: Eudeba, 1994.

CURCIO, M. Tratamiento de las exportaciones de servicios en el impuesto sobre los ingresos brutos en el ámbito de la provincia de Santa Fe: nuevo enfoque para su tratamiento basado en la equidad. Ponencia en el ler Congreso de Economía Provincial Santa Fe 2015, en Rosario, 2005.

DE MATTOS, C. Globalización, movimientos del capital, mercados de trabajo y concentración territorial expandida, en CASTELLO, I, y otros (Org.) Fronteiras na América Latina. Porto Alegre: FEE-Editora da Universidade, Universidade Federal de Río Grande do Sul, 1997.

DEL BONO, A. y HENRY, L. Tercerización de servicios en la Argentina: empleo y gestión de RRHH en los CC. Sistema de Información para la evaluación y el monitoreo del empleo, el trabajo y la inclusión social, Bs. As.: PNUD ARG/04/03, Ministerio de Trabajo, Empleo y Seguridad Social, 2009. 
FARCY, E. Nuevas tecnologías, trabajo inmaterial y luchas por derechos. Un análisis de los CC en la provincia de Córdoba. Ponencia presentada en las XVII Jornadas de Jóvenes Investigadores, en Córdoba, 2009.

GATTO, F. Crecimiento económico y desigualdades territoriales: algunos límites estructurales para lograr una mayor equidad. En Kosacoff (comp.) Crisis, recuperación y nuevos dilemas. La economía argentina 2002-2007. Buenos Aires: Oficina de CEPAL, 2007.

GARRO, S. Entre el hecho y el derecho: flexibilidad laboral y call centers en la Argentina postdevaluación. Ponencia IX Jornadas América Latina en el Nuevo Milenio: procesos, Crisis y Perspectivas en Facultad de Filosofía Universidad de Chile, 2008.

KOSACOFF, B. Crisis, recuperación y nuevos dilemas. La economía argentina 20022007. Buenos Aires: Oficina de CEPAL, 2007.

KURI GAITÁN, A. Globalización, Estado y nueva geografía productiva. Paradigma Económico, pp 60-78, Distrito Federal, 2009.

LIPIETZ, A. y LEBORGNE, D. Nuevas tecnologías, nuevas formas de regulación. Algunas consecuencias espaciales, en ALBUNQUERQUE LLORENS, DE MATTOS, C. y JORDÁN FUCH, R. (eds.) Revolución tecnológica y reestructuración productiva: impactos y desafios territoriales. Bs As: ILPES/ONU, Instituto de Estudios Urbanos de la Pontificia Universidad Católica, Grupo Editor Latinoamericano, 1990.

MÉNDEZ, R. Geografía económica. La lógica espacial del capitalismo global. Barcelona: Ariel Geografía, 1997.

MOENCH, E. Las actividades económicas globales y el espacio urbano: transformaciones socioterritoriales en torno a la localización de call centers en Argentina. Revista Geographos, Volumen 2, Nro. 8, 2011. Disponible:

$<$ http://web.ua.es/revista-geographos-giecryal $>$

OSZLAK, O. "Formación histórica del Estado en América Latina: elementos teórico metodológicos para su estudio". Estudios CEDES, volumen 1, Nro 3, Bs. As, 1978.

OSZLAK, O. Estado y Sociedad: ¿nuevas reglas de juego? Revista Reforma y Democracia, CLAD, Nro 9, octubre, pp. 7-60, Caracas, 1997.

PANAIA, M. Apuntes para la rediscusión del concepto de región en la Argentina actual. Revista de Estudios regionales, pp. 225-246, 2004.

SASSEN, S. Embedding the global in the national. en SMITH, D., SOLINGER, D. y TOPIK, S. States and Sovereignty in the Global Economy. Londres: Ed. Routledge, 1999. 
SASSEN, S. Territorio, autoridad y derechos. De los ensamblajes medievales a los ensamblajes globales. Bs. As.: Katz Editores, 2010.

SCHORR, M. Mitos y realidades del pensamiento neoliberal: la evolución de la industria manufacturera argentina durante la década de los noventa". En VARIOS AUTORES Más allá del pensamiento único. Bs As: Ed. CLACSO, 2002. 